\title{
The prevalence of stroke and related risk factors among residents aged $\geq 40$ years in Chongqing, Southwest China
}

\author{
Yin Yang ${ }^{1} \cdot$ Yalan Yang ${ }^{2} \cdot$ Ge Jin $^{3} \cdot$ Yongtao Yang ${ }^{3} \cdot$ Liang Chen $^{3} \cdot$ Zhongbi Jiang $^{3} \cdot$ Li Xie $^{1} \cdot$ Li Liu $^{3} \cdot$ Dewei Zeng $^{4}$. \\ Qunling Zhan ${ }^{3} \cdot$ Zhaohui Zhong $^{1}$ (D)
}

Received: 17 April 2019 / Accepted: 24 September 2019 / Published online: 7 April 2020

(C) The Author(s) 2019

\begin{abstract}
Background China bears the largest global stroke burden, yet little is known about its rates in Chongqing, southwest China. We aimed to investigate the prevalence and related risk factors for stroke in Chongqing, and to provide evidence for improved formulation of targeted primary preventive measures for stroke.

Methods In 2015, a cross-sectional study was conducted in Nan'an district, Chongqing. Participants responded to a questionnaire surveying general information and common risk factors for stroke, and related physical examinations were conducted.

Results Of 25,000 people aged $\geq 40$ years who were investigated, 24,859 participants completed the questionnaire and underwent the physical examination. The crude prevalence rate for stroke was $1.71 \%$, and was higher in men than in women $(1.9 \%$ versus $1.6 \%)$. Prevalence rates increased with age $(p<0.001)$. Multiple logistic regression analysis indicated that too little exercise, hypertension, family history of stroke, and history of transient ischemic attack were stroke risk factors among three groups (men, women, and total participants; all $p$-values $<0.05$ ). Smoking was a risk factor for men (odds ratio $2.77 ; 95 \% \mathrm{Cl}$ $1.46-5.28)$ and having only attained a primary school or lower education level was a risk factor for women $(p<0.05)$.

Conclusions These findings suggest that controlling stroke risk factors for stroke prevention is still crucial. Moreover, this study provides comprehensive resource data for further stroke research in southwest China.
\end{abstract}

Keywords Epidemiology $\cdot$ Stroke $\cdot$ Prevalence $\cdot$ Risk factors $\cdot$ Community-based study

\section{Introduction}

Yin Yang and Yalan Yang contributed equally to this work.

Qunling Zhan

aczhan@163.com

Zhaohui Zhong

357296750@qq.com

1 Department of Epidemiology, School of Public Health and Management, Research Center for Medicine and Social Development, Innovation Center for Social Risk Governance in Health, Chongqing Medical University, YiXueYuan Road, YuZhong District, Chongqing 400016, China

2 School of Public Health and Management, Chongqing Three Gorges Medical College, Chongqing, China

3 Department of Neurology, The Fifth People's Hospital of Chongqing, Renji Road, Nan 'an District, Chongqing 400062, China

4 Center for Disease Control and Prevention of Nan 'an District, Chongqing, China
Stroke is an acute cerebrovascular event characterized by high morbidity, high mortality, high disability, and high recurrence rates, and mainly manifests with signs and symptoms of cerebral ischemia or hemorrhagic injury (Hankey 2017). It is one of the leading causes of death and disability globally, accounting for approximately 5.78 million deaths worldwide, with 137 million disability-adjusted life-years lost in 2016 (Johnston et al. 2009; WHO 2016). Additionally, stroke has potentially enormous emotional and socioeconomic effects on patients, their families, and health services.

Over the past years, China has experienced rapid healthrelated and sociodemographic changes that have affected the prevalence of common risk factors for stroke (Yang et al. 2013; Zhou et al. 2016). According to a recent study of 480,687 participants, the stroke burden in China has increased over the last 30 years (Wang et al. 2017). It is now emerging as the primary leading cause of death and the second leading cause of life years lost in China (Tsai et al. 2013). Therefore, strokes remain a major health problem. 
The increasing burden and costs associated with care for patients with stroke point towards a pressing need for effective measures with regard to stroke prevention (Pandian Jeyaraj et al. 2018). The best possible implementation of primary preventive actions for strokes would ideally be the most optimal strategy, since they have been proven to be more effective than any secondary preventive measure (Heller et al. 2000). Moreover, primary preventive measures can be applied to a larger number of people compared to secondary preventive measures (Zhao et al. 2013).

Investigating the distribution prevalence of high-risk factors is critical for primary prevention of stroke. We therefore undertook stroke screening and risk-factor screening for residents aged $\geq 40$ years in five towns and five streets of Chongqing, to provide evidence for improved formulation of targeted primary preventive measures for stroke, and to provide data resources for further stroke research in southwest China.

\section{Materials and methods}

\section{Study design and participants}

Multistage random cluster sampling was used to select participants. In the first stage, five streets (Dan Zishi Street, Long Menhao Street, Nanping Street, Haitang Creek Street, Garden Road Street) and five towns (Tushan Town, Changsheng Bridge Town, Xiakou Town, Yinglong Town, Guangyang Town) were selected from eight streets and seven towns in Nan'an district, Chongqing. In the second stage, cluster sampling was used to select residents aged $\geq 40$ years.

All participants were identified according to the following inclusive and exclusive criteria. Criteria for inclusion were: Chongqing permanent residents who were registered in household registration or resident file systems, aged $\geq 40$ years, and living in the selected county for at least 6 months. The exclusion criteria were a previous diagnosis of neuropathy, psychosis, or unclear speech, and being a member of a floating population or a temporary resident.

Basic information concerning eligible permanent residents who met our inclusion criteria was obtained from household registration and resident file systems. Participants were informed of the study purpose and content by phone.

\section{Data collection}

From May 21, 2015 to September 30, 2015 trained investigators interviewed participants face-to-face to collect information. The survey involved two stages of interviews. During the first stage, investigators collected informed consent forms and completed a preliminary screening form that included basic information concerning sex, age, marital status, educational level, and personal habits (too little exercise, smoking), along with information concerning personal and family medical history of stroke and chronic diseases [hypertension, diabetes mellitus (DM), dyslipidemia, obesity, family history of stroke, previous history of transient ischemic attack (TIA), atrial fibrillation]. Moreover, participants' height, weight, blood pressure, and laboratory examinations of serum lipids [total cholesterol, low-density lipoprotein cholesterol (LDL-C), highdensity lipoprotein cholesterol (HDL-C), triglycerides), and fasting plasma glucose (FPG)] were examined by staff from both street community health service centers and the town hospitals. Community health service centers are non-profit, grassroots medical institutions which serve communities, families, and residents. These centers are the equivalents of the Western primary care service. They constitute a comprehensive, low-cost, efficient, and convenient health service system that integrates prevention and health care, general medical treatment, maternal and child health care, rehabilitation treatment, health education, immunization, and family planning guidance. A total of 25,000 people were investigated, of whom 24,859 participants completed both the questionnaire and the physical examination, with an effective rate of $99.4 \%$.

In the second stage, after preliminary screening, those who met the high-risk criteria for stroke were referred to community health centers for further examination, including blood tests, an electrocardiogram, and a carotid ultrasound scan.

Data collectors from the street community health service centers and township health centers collated and summarized the screening data at the same time every month, and reported the data of the previous month to the Screening and Intervention Data Center for High-Risk Stroke Populations prior to the 10th of each month. The organization and coordination of both stages of the survey were undertaken by staff at local Centers for Disease Control and Prevention (CDC).

\section{Diagnostic criteria}

The diagnostic criteria for stroke were based on World Health Organization criteria, with stroke being defined as 'rapidly developing clinical signs of focal (or global) disturbance of cerebral function, lasting more than 24 hours or leading to death, with no apparent cause other than that of vascular origin' (Aho et al. 1980). Any nervous system abnormalities induced due to trauma, metabolic disorder, tumor, or central nervous system infections were excluded.

Information on marital status, educational level, and age were based on self-reported responses. Hypertension was defined as a systolic blood pressure of $\geq 140 \mathrm{mmHg}$ or a diastolic blood pressure of $\geq 90 \mathrm{mmHg}$, or any use of antihypertensive medication or a self-reported history of hypertension. DM was defined as a fasting blood glucose $\geq 7.0 \mathrm{mmol} / \mathrm{l}$, or any use of antidiabetic medication or a 
self-reported history of DM. Dyslipidemia status was based on the 2007 Guidelines for Prevention and Treatment of Dyslipidemia in Chinese Adults (Joint Committee for Developing Chinese Guidelines on Prevention and Treatment of Dyslipidemia in Adults 2007). A family history of stroke was defined as $\geq 1$ person having a history of stroke among first-degree relatives. Smoking was defined as smoking $\geq 1$ cigarette daily, and a duration of continuous smoking was defined as $\geq 12$ months. Too little exercise was defined as exercise $\leq 3$ times per week, $\leq 30 \mathrm{~min}$ each session, and $<12$ months in duration, except for those employed in moderate to heavy manual work. Body mass index (BMI) was calculated as weight in kilograms divided by the square of height in meters, and being overweight or obese was defined as a BMI $\geq 24 \mathrm{~kg} / \mathrm{m}^{2}$.

\section{Statistical analysis}

We used Epidata 3.1 software for data entry. Descriptive statistics were used to summarize the overall characteristics of the study population, and statistical analysis was performed using IBM SPSS version 22.0. Pearson's chi-squared test was used to compare the prevalence of stroke in participants according to sex, personal habits (smoking, too little exercise), personal illness (hypertension, DM, dyslipidemia, atrial fibrillation, being overweight or obese), and family history of stroke. The prevalence of stroke in the categories grouped according to age and education level was compared using the chi-squared test for trend.

Controls were then paired to cases of the same age and sex according to the 1:1 matched case-control study principle. Binary logistic regression models were employed to investigate the risk factors associated with stroke and the results were reported as odds ratios (ORs) with $95 \%$ confidence intervals (CIs). A $p$ value of $<0.05$ was considered statistically significant.

\section{Quality control}

Quality control was implemented in all phases of the survey and in the supervised preparations, field work, and data processing. All investigators from the street community health service centers received standardized training, including how to communicate with participants, how to measure blood pressure, height, and weight, and how to collect blood samples. Quality control personnel reviewed all questionnaires and physical measurement forms after daily surveys had been undertaken, and telephone contact was made with any participant who had not fully completed the data or whose data showed logistic errors. A real-time double-entry method was used for data entry verification.

\section{Results}

\section{Study participants' basic characteristics}

A total of 25,000 questionnaires was completed in this survey, of which 24,859 were available after confirming the validity of each questionnaire, with an effective rate of $99.4 \%$. Overall, the estimated prevalence of stroke among the study participants in Chongqing was $1.7 \%$.

Table 1 shows the interviewees' basic characteristics. In this study, the sex ratio (women versus men) was approximately 1.69:1 (62.8\%:37.2\%), and 95.5\% of enrolled participants were aged between 40 and 79 years. Age distribution and age grouped according to sex are shown in Table 1 and in Fig. 1. Most of the respondents had a BMI ranging from $18.5 \mathrm{~kg} / \mathrm{m}^{2}$ to $25.9 \mathrm{~kg} / \mathrm{m}^{2}$, accounting for approximately $77.4 \%$ of the study participants. Overall, around $66 \%$ of participants had attained an educational level of middle school or above, and married interviewees comprised the largest percentage (91.9\%).

\section{Prevalence of stroke among people aged $\geq \mathbf{4 0}$ years in Chongqing}

Table 2 shows the stroke prevalence rate based on selected demographic characteristics, personal habits, and individual illnesses of participants. We found that the prevalence rate for stroke was lowest among participants aged 40 to 49 years $(0.8 \%)$ and that the prevalence in different age groups increased with age $(p<0.05)$. We also found that the stroke prevalence was significantly lower among married people than among unmarried people (single, divorced, widowed, or other) $(p<0.05)$.

Our analysis revealed that participants with different educational levels had different prevalence rates for stroke $(p<0.05)$, with those having been at a junior college or undergraduate level showing the highest prevalence (2\%). We further estimated the prevalence of stroke according to total participants, male participants, and female participants (Fig. 2). Our results showed that the rate for stroke was higher in men than in women, except for those aged between 60 and 69 years, with the highest prevalence in the three groups occurring among people aged $\geq 80$ years $(2.4 \%)$.

Similarly, we also found an association between stroke prevalence and participants' personal habits and illnesses. We found a significantly higher prevalence in participants who smoked $(p<0.01)$, who engaged in limited physical exercise $(p<0.001)$, and who were overweight or obese (BMI $\left.\geq 24 \mathrm{~kg} / \mathrm{m}^{2}, p<0.001\right)$.

\section{Analysis of risk factors related to stroke}

We performed a 1:1 match of 425 patients with stroke to 425 controls, according to age and sex. A chi-squared analysis 
Table 1 Basic characteristics of study participants

\begin{tabular}{|c|c|c|c|}
\hline Characteristic & Category & Number & Percentage $(\%)$ \\
\hline \multirow[t]{2}{*}{ Subject } & Stroke patient & 425 & 1.7 \\
\hline & Non-stroke patient & 24,434 & 98.3 \\
\hline \multirow[t]{2}{*}{ Sex } & Male & 9243 & 37.2 \\
\hline & Female & 15,616 & 62.8 \\
\hline \multirow[t]{6}{*}{ Age (years) } & $40-49$ & 3768 & 15.2 \\
\hline & $50-59$ & 6118 & 24.6 \\
\hline & $60-69$ & 9409 & 37.8 \\
\hline & $70-79$ & 4443 & 17.9 \\
\hline & $80-89$ & 1049 & 4.2 \\
\hline & $90-$ & 72 & 0.3 \\
\hline \multirow[t]{4}{*}{ BMI $\left(\mathrm{kg} / \mathrm{m}^{2}\right)$} & $<18.5$ & 624 & 2.5 \\
\hline & $18.5-23.9$ & 13,695 & 55.1 \\
\hline & $\geq 24$ & 10,486 & 42.2 \\
\hline & Not available & 54 & 0.2 \\
\hline \multirow[t]{5}{*}{ Marital status } & Single & 149 & 0.6 \\
\hline & Married & 22,846 & 91.9 \\
\hline & Divorced & 1596 & 6.4 \\
\hline & Widowed & 251 & 1.0 \\
\hline & Other & 17 & 0.1 \\
\hline \multirow[t]{5}{*}{ Education level } & Primary school or lower & 8466 & 34.1 \\
\hline & Middle school & 9661 & 38.9 \\
\hline & Secondary specialised school or high school & 4951 & 19.9 \\
\hline & Junior college or undergraduate & 1713 & 6.9 \\
\hline & Postgraduate or higher & 68 & 0.3 \\
\hline
\end{tabular}

BMI: body mass index

showed the baseline profile of the controls and the participants with stroke among the three groups (men, women, and total study population) (Table 3). Significant factors found in the chi-squared analysis within the three groups were included in the unconditional logistic regression model for multivariate analysis.

Multivariate regression analysis showed that too little exercise, hypertension, family history of stroke, and history of

Fig. 1 Age distribution according to sex of study participants in Chongqing, southwest China

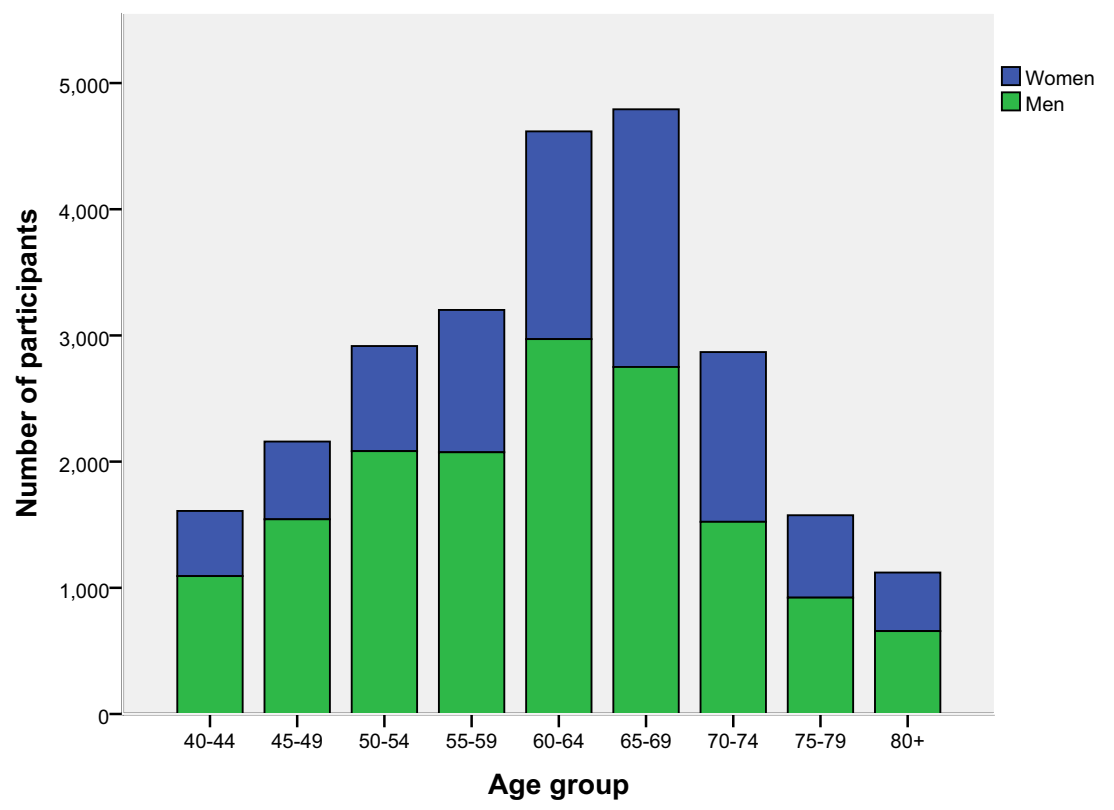


Table 2 Prevalence of stroke in study participants aged $\geq 40$ years

\begin{tabular}{|c|c|c|c|c|c|}
\hline Characteristic & $\begin{array}{l}\text { Number of } \\
\text { participants }\end{array}$ & $\begin{array}{l}\text { Number of } \\
\text { cases }\end{array}$ & $\begin{array}{l}\text { Prevalence } \\
(\%)\end{array}$ & $x^{2}$ & $P$ value \\
\hline \multicolumn{4}{|l|}{ Sex } & 2.002 & 0.157 \\
\hline Male & 9243 & 172 & 1.9 & & \\
\hline Female & 15,616 & 253 & 1.6 & & \\
\hline \multicolumn{4}{|l|}{ Age (years) ${ }^{\mathrm{a}}$} & 34.045 & $<0.001^{*}$ \\
\hline $40-49$ & 3768 & 30 & 0.8 & & \\
\hline $50-59$ & 6118 & 87 & 1.4 & & \\
\hline $60-69$ & 9409 & 185 & 2.0 & & \\
\hline $70-79$ & 4443 & 96 & 2.2 & & \\
\hline $80-$ & 1121 & 27 & 2.4 & & \\
\hline \multicolumn{4}{|l|}{ Marital status } & 5.936 & $0.015^{*}$ \\
\hline Married & 22,846 & 377 & 1.7 & & \\
\hline Unmarried & 2013 & 48 & 2.4 & & \\
\hline \multicolumn{4}{|l|}{ Education level $^{\mathrm{b}}$} & 11.304 & $0.023^{*}$ \\
\hline Primary school or lower & 8466 & 158 & 1.9 & & \\
\hline Middle school & 9661 & 173 & 1.8 & & \\
\hline $\begin{array}{l}\text { Secondary specialised school or } \\
\text { high school }\end{array}$ & 4951 & 58 & 1.2 & & \\
\hline Junior college or undergraduate & 1713 & 35 & 2.0 & & \\
\hline Postgraduate or higher & 68 & 1 & 1.5 & & \\
\hline \multicolumn{4}{|l|}{ Smoking } & 12.047 & $0.001^{*}$ \\
\hline No & 21,484 & 343 & 1.6 & & \\
\hline Yes & 3375 & 82 & 2.4 & & \\
\hline \multicolumn{4}{|c|}{ Overweight or obese (BMI $\left.\geq 24 \mathrm{~kg} / \mathrm{m}^{2}\right)$} & 23.008 & $<0.001^{*}$ \\
\hline No & 14,337 & 196 & 1.4 & & \\
\hline Yes & 10,486 & 227 & 2.2 & & \\
\hline \multicolumn{4}{|l|}{ Too little physical exercise } & 22.605 & $<0.001^{*}$ \\
\hline No & 20,327 & 310 & 1.5 & & \\
\hline Yes & 4532 & 115 & 2.5 & & \\
\hline \multicolumn{4}{|l|}{ Hypertension } & 206.674 & $<0.001^{*}$ \\
\hline No & 15,765 & 128 & 0.8 & & \\
\hline Yes & 9094 & 297 & 3.3 & & \\
\hline \multicolumn{4}{|l|}{ Dyslipidemia } & 9.987 & $0.002^{*}$ \\
\hline No & 16,301 & 248 & 1.5 & & \\
\hline Yes & 8558 & 177 & 2.1 & & \\
\hline \multicolumn{4}{|l|}{ Diabetes } & 22.667 & $<0.001^{*}$ \\
\hline No & 22,626 & 359 & 1.6 & & \\
\hline Yes & 2233 & 66 & 3.0 & & \\
\hline \multicolumn{4}{|l|}{ Atrial fibrillation } & 6.403 & $0.011^{*}$ \\
\hline No & 24,512 & 413 & 1.7 & & \\
\hline Yes & 347 & 12 & 3.5 & & \\
\hline \multicolumn{4}{|l|}{ Family history of stroke } & 535.994 & $<0.001^{*}$ \\
\hline No & 21,863 & 263 & 1.2 & & \\
\hline Yes & 1894 & 162 & 8.6 & & \\
\hline \multicolumn{6}{|l|}{ History of TIA } \\
\hline No & 22,827 & 282 & 1.2 & 1284.427 & $<0.001^{*}$ \\
\hline Yes & 735 & 140 & 19.0 & & \\
\hline
\end{tabular}

${ }^{*}: P<0.05 ;{ }^{a}:$ Trend chi-square test $p<0.001 ;{ }^{b}:$ Trend chi-square test $p=0.122$; TIA: transient ischemic attack; Unmarried $=$ single, divorced, widowed, or other 
Fig. 2 Prevalence rate for stroke according to age and sex

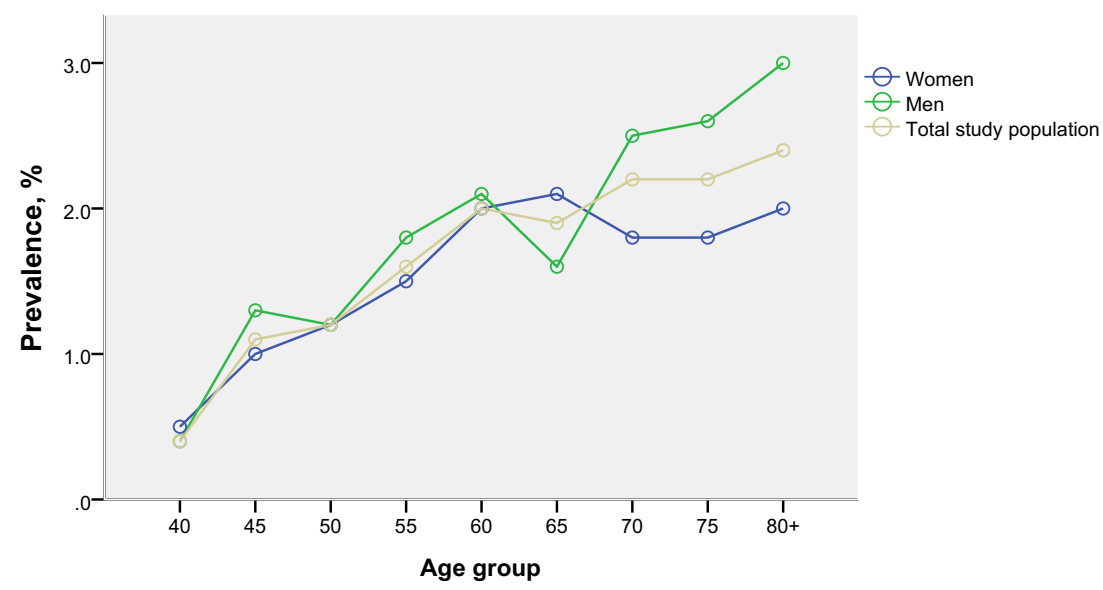

TIA were risk factors associated with stroke among the groups. Smoking was not a risk factor in women; education level was not a risk factor in men (Table 4). The assignment of logistic regression analysis variables is shown in Table 5.

\section{Discussion}

In recent years, with rapid changes in lifestyle and age structure in China, the epidemiological features of stroke may have altered accordingly. Updated data on stroke epidemiology are therefore needed to help in strategic planning concerning the prevention and management of stroke (Liu et al. 2007). We used a cross-sectional study design to investigate the prevalence of stroke and its related risk factors among residents aged $\geq 40$ years who were selected from five towns and five streets in Chongqing, one of the fastest developing cities in southwest China.

The main study findings are summarized as follows. First, the survey showed that the crude prevalence rate for stroke in residents aged $\geq 40$ years in Chongqing was $1.71 \%$, with a higher prevalence rate in men, and that the prevalence rates for

Table 3 Baseline profile of controls and patients with stroke in different groups

\begin{tabular}{|c|c|c|c|c|c|c|c|c|c|}
\hline & \multicolumn{3}{|l|}{ Men } & \multicolumn{3}{|l|}{ Women } & \multicolumn{3}{|l|}{ Total } \\
\hline & $\begin{array}{l}\text { Case: } \\
n(\%)\end{array}$ & Control: $n(\%)$ & $P$ & $\begin{array}{l}\text { Case: } \\
n(\%)\end{array}$ & Control: $n(\%)$ & $P$ & $\begin{array}{l}\text { Case: } \\
n(\%)\end{array}$ & Control: $n(\%)$ & $P$ \\
\hline Subjects & 172 & 172 & & 253 & 253 & & 425 & 425 & \\
\hline Education level & & & $0.030^{\zeta}$ & & & $<0.001^{\zeta}$ & & & $<0.001^{\zeta}$ \\
\hline Primary school or lower & $53(30.8)$ & $28(16.3)$ & & $105(14.5)$ & $55(21.7)$ & & $158(37.2)$ & $83(19.5)$ & \\
\hline Middle school & $72(41.9)$ & $82(47.7)$ & & $101(39.9)$ & $131(51.8)$ & & $173(40.7)$ & $213(50.1)$ & \\
\hline $\begin{array}{l}\text { Secondary specialised school } \\
\text { or high school }\end{array}$ & $26(15.1)$ & $36(20.9)$ & & $32(12.6)$ & $56(22.1)$ & & $58(13.6)$ & $92(21.6)$ & \\
\hline Junior college or undergraduate & $20(11.6)$ & $24(14.0)$ & & $15(5.9)$ & $11(4.3)$ & & $35(8.2)$ & $35(8.2)$ & \\
\hline Postgraduate or higher & $1(0.6)$ & $2(1.2)$ & & - & - & & $1(0.2)$ & $2(0.5)$ & \\
\hline Married & $162(94.2)$ & $167(97.1)$ & 0.187 & $215(85.0)$ & $232(91.7)$ & $0.019^{\zeta}$ & $377(88.7)$ & $399(93.9)$ & $0.007^{\zeta}$ \\
\hline Smoking & $77(44.8)$ & $30(17.4)$ & $<0.001^{\zeta}$ & $5(2.0)$ & $6(1.2)$ & 0.737 & $82(19.3)$ & $34(8.0)$ & $<0.001^{\zeta}$ \\
\hline $\begin{array}{l}\text { Overweight or obese } \\
\quad\left(\mathrm{BMI} \geq 24 \mathrm{~kg} / \mathrm{m}^{2}\right)\end{array}$ & $85(50.0)$ & $70(40.9)$ & 0.093 & $142(56.1)$ & $114(45.1)$ & $0.013^{\zeta}$ & $227(53.7)$ & $184(43.4)$ & $0.003^{\zeta}$ \\
\hline Too little physical exercise & $47(27.3)$ & $17(9.9)$ & $<0.001^{\zeta}$ & $68(26.9)$ & 30 (11.9) & $<0.001^{\zeta}$ & $115(27.1)$ & $47(11.1)$ & $<0.001^{\zeta}$ \\
\hline Hypertension & $132(76.7)$ & $52(30.2)$ & $<0.001^{\zeta}$ & $165(65.2)$ & $85(33.6)$ & $<0.001^{\zeta}$ & 297 (69.9) & $137(32.2)$ & $<0.001^{\zeta}$ \\
\hline Dyslipidemia & $72(41.9)$ & $61(35.5)$ & 0.223 & $105(41.5)$ & $94(37.2)$ & 0.317 & $177(41.6)$ & $155(36.5)$ & 0.122 \\
\hline Diabetes & $26(15.1)$ & $19(11.0)$ & 0.263 & $40(15.8)$ & $20(7.9)$ & $0.006^{\zeta}$ & $66(15.5)$ & $39(9.2)$ & $0.005^{\zeta}$ \\
\hline Atrial fibrillation & $4(2.3)$ & $3(1.7)$ & 0.703 & $8(3.2)$ & $6(2.4)$ & 0.588 & $12(2.8)$ & $9(2.1)$ & 0.507 \\
\hline Family history of stroke & $57(33.1)$ & $7(4.3)$ & $<0.001^{\zeta}$ & $105(41.5)$ & $19(7.6)$ & $<0.001^{\zeta}$ & $162(38.1)$ & $26(6.1)$ & $<0.001^{\zeta}$ \\
\hline History of TIA & $51(29.8)$ & $2(1.2)$ & $<0.001^{\zeta}$ & $89(35.5)$ & $3(1.2)$ & $<0.001^{\zeta}$ & $140(32.9)$ & $5(1.2)$ & $<0.001^{\zeta}$ \\
\hline
\end{tabular}

$r^{r}: P<0.05$; TIA: transient ischemic attack

: $P<0.05$; OR: odds ratio; CI: confidence interval; BMI: body mass index; TIA: transient ischemic attack 
Table 4 Multivariate logistics regression analysis of risk factors associated with stroke in Chongqing

\begin{tabular}{|c|c|c|c|c|c|c|c|c|c|}
\hline & \multicolumn{3}{|l|}{ Men } & \multicolumn{3}{|l|}{ Women } & \multicolumn{3}{|l|}{ Total } \\
\hline & OR & $95 \% \mathrm{CI}$ & $P$ & OR & $95 \% \mathrm{CI}$ & $P$ & OR & $95 \% \mathrm{CI}$ & $P$ \\
\hline \multicolumn{10}{|l|}{ Education level } \\
\hline Primary school or lower & - & - & - & Reference & & & Reference & & \\
\hline Middle school & - & - & - & 0.54 & $0.32-0.91$ & 0.022 & 0.55 & $0.36-0.85$ & 0.007 \\
\hline Secondary specialised school or high school & - & - & - & 0.30 & $0.15-0.60$ & 0.001 & 0.34 & $0.19-0.58$ & $<0.001$ \\
\hline Junior college or undergraduate & - & - & - & 1.00 & $0.36-2.73$ & 0.993 & 0.62 & $0.32-1.21$ & 0.163 \\
\hline Postgraduate or higher & - & - & - & - & - & - & 0.63 & $0.04-11.52$ & 0.757 \\
\hline Smoking & 2.77 & $1.46-5.28$ & 0.002 & - & - & - & 2.24 & $1.31-3.83$ & 0.003 \\
\hline Overweight or obese (BMI $\geq 24 \mathrm{~kg} / \mathrm{m}^{2}$ ) & - & - & - & - & - & - & 1.57 & $1.02-2.41$ & 0.038 \\
\hline Too little physical exercise & 3.03 & $1.29-7.11$ & 0.011 & 1.95 & $1.07-3.55$ & 0.029 & 2.17 & $1.33-3.54$ & 0.002 \\
\hline Hypertension & 8.69 & $4.67-16.17$ & $<0.001$ & 3.97 & $2.50-6.30$ & $<0.001$ & 5.32 & $3.68-7.70$ & $<0.001$ \\
\hline Family history of stroke & 5.33 & $2.11-13.46$ & $<0.001$ & 5.44 & $2.98-9.92$ & $<0.001$ & 5.72 & $3.46-9.47$ & $<0.001$ \\
\hline History of TIA & 30.51 & $6.53-142.62$ & $<0.001$ & 35.71 & $10.64-119.78$ & $<0.001$ & 32.87 & $12.75-84.74$ & $<0.001$ \\
\hline
\end{tabular}

different age groups increased with age. Second, too little exercise, hypertension, family history of stroke, history of TIA, smoking, and education levels were risk factors associated with stroke in Chongqing.

Stroke prevalence rates in China have been reported to differ according to ethnicity, region, and age (Wang et al. 2017). In Jilin, north China, the prevalence rate of stroke among residents aged $\geq 40$ years has been reported to be $7.2 \%$ (Zhang et al. 2017), and in Shenzhen, south China, it has been found to be $2.21 \%$ (Gan et al. 2017). Our study showed a lower prevalence of $1.7 \%$. These findings confirm regional differences in stroke prevalence rates among people aged $\geq 40$ years in China, with the overall characteristics having been reported to be high in the north and low in the south
(Wang et al. 2017). There was a higher percentage of women in this study, for whom the prevalence rates for stroke have been reported to be lower (Yang et al. 2004). This may be one reason why we have a lower overall prevalence.

The stratified analysis showed that the prevalence rate in men was slightly higher than in women (1.9\% versus $1.6 \%)$, which is consistent with global prevalence data. According to an analysis by Feigin et al. (2009) involving 56 countries and regions, the ratio of male-to-female stroke prevalence was 1.41: 1. From 1986 to 2000, an investigation in China showed that the ratio of male-to-female stroke incidence was 1.28:11.81:1 (Yang et al. 2004), which was also similar to the results of another study (Cheng et al. 1995) and may possibly be related to a more unhealthy male lifestyle that includes risk
Table 5 Assignment of logistic regression analysis variables

\begin{tabular}{ll}
\hline Variables & Value \\
\hline Stroke & Yes $=1$, No $=0$ \\
Education & Primary school or lower $=1$, middle school $=2$, \\
& secondary specialised school or high school $=3$, \\
& junior college or undergraduate =4, postgraduate or higher $=5$ \\
Marital status & Married $=1$, unmarried (single, divorced, widowed, or other) $=0$ \\
Hypertension & Yes $=1$, no $=0$ \\
Dyslipidemia & Yes $=1$, no $=0$ \\
Overweight or obese & Yes $=1$, no $=0$ \\
Too little physical exercise & Yes $=1$, no $=0$ \\
Smoking & Yes $=1$, no $=0$ \\
Diabetes & Yes $=1$, no $=0$ \\
Family history of stroke & Yes $=1$, no $=0$ \\
Atrial fibrillation & Yes $=1$, no $=0$ \\
History of TIA & Yes $=1$, no $=0$ \\
\hline
\end{tabular}

TIA: transient ischemic attack 
factors such as smoking and alcohol consumption (Zhang et al. 2014).

Our results also showed that hypertension was the most important independent risk factor for stroke (OR 4.958, 95\% CI 3.42-7.20), in accordance with other studies (Jia et al. 2011; Nogueira 2013). One large sample study of stroke conducted by O'Donnell et al. (O'Donnell et al. 2010) confirmed that ten stroke risk factors were statistically significant, in which hypertension played a major role. Psaty et al. (2001) found that each $10 \mathrm{mmHg}$ increase in blood pressure correspondingly increased the risk of stroke 1.4 to 1.8 times. The use of antihypertensive medication to control blood pressure in patients with a history of stroke can effectively reduce the risk of stroke recurrence by $24 \%$ and lower the risk of nonfatal stroke by $21 \%$ (Rashid et al. 2003). In a follow-up study of more than 70,000 hypertensive patients, the risk of death due to stroke was three times greater in those who did not take antihypertensive drugs than in those who did (Herttua et al. 2013). Therefore, effective control of hypertension can significantly reduce the occurrence of stroke. Standardizing the diagnosis and treatment of hypertension in the community, improving patients' early awareness of hypertension, and closely monitoring blood pressure are all necessary to prevent stroke.

Dyslipidemia is an important risk factor for the onset of cardiovascular and cerebrovascular diseases. However, the prevalence of stroke due to dyslipidemia in our study was only $2.1 \%$. In the logistic multivariate regression analysis, dyslipidemia was not statistically significant. The results of studies concerning the relationship between stroke and dyslipidemia remain controversial. Some observational epidemiological studies have found no correlation between high levels of total cholesterol or low-density lipoprotein and stroke (Willey et al. 2009; Psaty et al. 2004). Moreover, one meta-analysis comprising 61 prospective studies failed to find a positive association between cholesterol and stroke death, particularly in elderly or hypertensive patients (Strong et al. 2007). However, other studies have shown the opposite (He et al. 2004), indicating that there remains a lack of effective evidence-based studies concerning the relationship between dyslipidemia and stroke. The reported relationship between different blood lipid components and different stroke types has also been inconsistent (Sun et al. 2019). Therefore, further investigations of the association between different lipid components and various types of stroke need to be conducted. However, before exact relationships can be demonstrated, controlling dyslipidemia should not be overlooked since, aside from potentially affecting the occurrence of stroke, dyslipidemia is also associated with the development of many other diseases.

Smoking is an important and controllable risk factor for cerebrovascular disease and has been shown to increase the risk of stroke 1.7 times (95\% CI 1.38-2.1) (Lou et al. 2018). The results of our study also showed that smokers have a 2.296-times higher risk of stroke (95\% CI 1.34-3.93) than non-smokers, and that the prevalence of stroke among smokers was $2.4 \%$ while among non-smokers it was $1.6 \%$. Both active and passive smoking have been shown to increase the incidence of atherosclerosis (Ádám et al. 2013). Many prospective follow-up studies have found that passive smoking has a close dose-response relationship with stroke (Oono et al. 2011). If passive smoking could be completely eliminated, the incidence of stroke would be reduced by $50 \%$ by 2040 (Fischer and Kraemer 2016). However, a systematic review and meta-analysis that included 3,980,359 participants in Asia showed that smoking did not contribute to the risk of stroke (Peters et al. 2013). In our study, we did not find a relationship between smoking and stroke prevalence in women. This may have been because women are more likely to be passive smokers, and passive smoking was not included in our study; therefore, the association between smoking and stroke in our study and in other studies should be interpreted with caution.

With the acceleration of social-economic development and urbanization, overweight and obese populations in China have been rapidly increasing. The results of this study showed that the stroke prevalence rate of people aged $\geq 40$ years who were overweight or obese was $2.6 \%$, and that this was higher than that of the general population (1.5\%). Multivariate analysis showed that the risk of stroke in overweight or obese people was 1.572 times (95\% CI 1.02-2.41) higher than that of the general population. These results were in accordance with evidence indicating that an increase of BMI and abdominal obesity are independent risk factors for stroke (Jensen et al. 2014). A meta-analysis including 25 observational studies showed that the risk of ischemic stroke in overweight and obese patients increased by $22 \%$ and $64 \%$ respectively, compared with the general population (Strazzullo et al. 2010). Obesity not only increases the risk of stroke but is also an independent risk factor for the prognosis of stroke. Studies in the United States, Japan, and China have found that patients with ischemic stroke and with a high BMI have longer hospitalization, more complications, higher disability, and worse prognosis (Strazzullo et al. 2010; Nakamura et al. 2006; Kalichman et al. 2007). Therefore, weight control should be addressed in terms of primary and secondary stroke prevention in China.

Furthermore, we found that certain uncontrollable factors, such as family history of stroke and a history of TIA, were high-risk factors associated with stroke, as also shown by two other studies with similar results (Knottnerus et al. 2011; Johnston et al. 2003). These findings indicate that prevention and treatment strategies for people with a positive family history of stroke should be strengthened.

This study has some limitations. First, because of the crosssectional design, we could not determine the causal relationship between the risk factors and stroke. Second, we did not 
measure alcohol consumption, which is related to stroke (Zhang et al. 2014). Furthermore, we did not perform a hierarchical analysis based on rural and urban areas, another aspect which also needs to be further studied and explored.

In conclusion, our study found that the crude prevalence rate of stroke in residents aged $\geq 40$ years in Chongqing was $1.71 \%$, and that hypertension, smoking, being overweight or obese, having a family history of stroke, and too little exercise were significant risk factors. Although the prevalence rate of stroke in Chongqing was lower than the reported national stroke prevalence rates in China, given the heavy burden on families and society, efforts are still needed to ensure effective treatment for patients. The data derived from this study are likely to serve as a resource for further stroke research in southwest China.

Acknowledgements The authors thank all the participants who volunteered for this study. We also thank the staff of the community health service centers, town hospitals, and Centers for Disease Control and Prevention for their support.

Author contributions Qunling Zhan \& Zhaohui Zhong were responsible for the study concept and design. Yin Yan and Yalan Yang did the fileld work and data analysis and manuscript preparation. Li Xie and Ge Jin, contributed to the data analysis. Yongtao Yang, Liang Chen and Zhongbi Jiang contributed to the field investigation and data collection, Li Liu and Dewei Zeng contributed to the quality control.

Funding This work was supported by funds from Chongqing Municipal Health Bureau Medical Research Plan Project (key project, serial number of grant: 2011-1-108).

\section{Compliance with ethical standards}

Ethics statement Research approval was granted by the Ethics Committee of Chongqing Fifth People's Hospital.

Conflict of interest The authors declare that they have no conflict of interest.

Open Access This article is distributed under the terms of the Creative Commons Attribution 4.0 International License (http://creativecommons. org/licenses/by/4.0/), which permits unrestricted use, distribution, and reproduction in any medium, provided you give appropriate credit to the original author(s) and the source, provide a link to the Creative Commons license, and indicate if changes were made.

\section{References}

Aho K, Harmsen P, Hatano S, Marquardsen J, Smirnov VE, Strasser T (1980) Cerebrovascular disease in the community: results of a WHO collaborative study. Bull World Health Organ 58:113-130

Ádám B, Molnár Á, Gulis G, Ádány R (2013) Integrating a quantitative risk appraisal in a health impact assessment: analysis of the novel smoke-free policy in Hungary. Eur J Pub Health 23:211-217
Cheng XM, Ziegler DK, Lai YH, Li SC, Jiang GX, Du XL et al (1995) Stroke in China, 1986 through 1990. Stroke 26:1990-1994

Fischer F, Kraemer A (2016) Health impact assessment for second-hand smoke exposure in Germany - quantifying estimates for Ischaemic heart diseases, COPD, and stroke. Int J Environ Res Public Health $13: 198$

Feigin V, Lawes C, Bennett D, Barkercollo S, Parag V (2009) Worldwide stroke incidence and early case fatality reported in 56 populationbased studies: a systematic review. Lancet Neurol 8:355-369

Gan Y, Wu J, Zhang S, Li L, Yin X, Gong Y et al (2017) Prevalence and risk factors associated with stroke in middle-aged and older Chinese: a community-based cross-sectional study. Sci Rep 7:9501

Hankey GJ (2017) Stroke. Lancet 389:641-654

He J, Dongfeng G, Kristi R et al (2004) Serum total and lipoprotein cholesterol levels and awareness, treatment, and control of hypercholesterolemia in China. Circulation 110:405-411

Herttua K, Tabák AG, Martikainen P, Vahtera J, Kivimäki M (2013) Adherence to antihypertensive therapy prior to the first presentation of stroke in hypertensive adults: population-based study. Eur Heart J 34:2933-2939

Heller RF, Langhorne P, James E (2000) Improving stroke outcome: the benefits of increasing availability of technology. Bull World Health Organ 78:1337-1343

Joint Committee for Developing Chinese Guidelines on Prevention and Treatment of Dyslipidemia in Adults (2007) Guidelines for the prevention and treatment of dyslipidemia in Chinese adults. Chin J Cardiol 35:190-419

Jensen MD, Ryan DH, Apovian CM, Ard JD, Comuzzie AG, Donato KA et al (2014) 2013 AHA/ACC/TOS guideline for the management of overweight and obesity in adults: a report of the American College of Cardiology/American Heart Association Task Force on Practice Guidelines and the Obesity Society. J Am Coll Cardiol 63:29853023

Jia Q, Liu L, Wang Y (2011) Risk factors and prevention of stroke in the Chinese population. J Stroke Cerebrovasc Dis 20:395-400

Johnston SC, Mendis S, Mathers CD (2009) Global variation in stroke burden and mortality: estimates from monitoring, surveillance, and modelling. Lancet Neurol 8:345-354

Johnston SC, Sidney S, Bernstein AL, Gress DR (2003) A comparison of risk factors for recurrent TIA and stroke in patients diagnosed with TIA. Neurology. 60:280-285

Knottnerus IL, Gielen M, Lodder J, Rouhl RP, Staals J, Vlietinck R et al (2011) Family history of stroke is an independent risk factor for lacunar stroke subtype with asymptomatic lacunar infarcts at younger ages. Stroke. 42:1196-1200

Kalichman L, Rodrigues B, Gurvich D, Israelov Z, Spivak E (2007) Impact of patient's weight on stroke rehabilitation results. Am J Phys Med Rehabil 86:650-655

Lou H, Dong Z, Pan Z et al (2018) Interaction of diabetes and smoking on stroke: a population-based cross-sectional survey in China. BMJ Open 8:e17706

Liu M, Wu B, Wang WZ, Lee LM, Zhang SH, Kong LZ (2007) Stroke in China: epidemiology, prevention, and management strategies. Lancet Neurol 6:456-464

Nogueira JB (2013) Hypertension, coronary heart disease and stroke: should the blood pressure J-curve be a concern? Rev Port Cardiol 32:139-144

Nakamura Y, Yamamoto T, Okamura T, Kadowaki T, Hayakawa T, Kita $Y$ et al (2006) Combined cardiovascular risk factors and outcome: NIPPON DATA80, 1980-1994. Circ J 70:960-964

Oono IP, Mackay DF, Pell JP (2011) Meta-analysis of the association between secondhand smoke exposure and stroke. J Public Health (Oxf) 33:496-502

O'Donnell MJ, Xavier D, Liu L, Zhang H, Chin SL, Rao-Melacini P et al (2010) Risk factors for ischaemic and intracerebral haemorrhagic 
stroke in 22 countries (the INTERSTROKE study): a case-control study. Lancet. 376:112-123

Psaty BM, Anderson M, Kronmal RA, Tracy RP, Orchard T, Fried LP et al (2004) The association between lipid levels and the risks of incident myocardial infarction, stroke, and total mortality: the Cardiovascular Health Study. J Am Geriatr Soc 52:1639-1647

Psaty BM, Furberg CD, Kuller LH, Cushman M, Savage PJ, Levine D et al (2001) Association between blood pressure level and the risk of myocardial infarction, stroke, and total mortality: the Cardiovascular Health Study. Arch Intern Med 161:1183-1192

Pandian Jeyaraj D, Gall Seana L, Kate Mahesh P et al (2018) Prevention of stroke: a global perspective. Lancet 392:1269-1278

Peters SA, Huxley RR, Woodward M (2013) Smoking as a risk factor for stroke in women compared with men: a systematic review and metaanalysis of 81 cohorts, including 3,980,359 individuals and 42,401 strokes. Stroke. 44:2821-2828

Rashid P, Leonardi-Bee J, Bath P (2003) Blood pressure reduction and secondary prevention of stroke and other vascular events: a systematic review. Stroke. 34:2741-2748

Strong K, Mathers C, Bonita R (2007) Preventing stroke: saving lives around the world. Lancet Neurol 6:182-187

Sun L, Robert C, Derrick B et al (2019) Causal associations of blood lipids with risk of ischemic stroke and intracerebral hemorrhage in Chinese adults. Nat Med 25:569-574

Strazzullo P, D'Elia L, Cairella G, Garbagnati F, Cappuccio FP, Scalfi L (2010) Excess body weight and incidence of stroke: meta-analysis of prospective studies with 2 million participants. Stroke. 41:e418e426

Tsai C-F, Brenda T, Sudlow CLM (2013) Epidemiology of stroke and its subtypes in Chinese vs white populations: a systematic review. Neurology 81:264-272
World Health Organization (2016) Global Health Estimates (GHE). WHO, Geneva http://www.who.int/healthinfo/global_burden_ disease/en/

Wang W, Jiang B, Sun H, Ru X, Sun D, Wang L et al (2017) Prevalence, incidence, and mortality of stroke in China. Circulation. 135:759771

Willey JZ, Xu Q, Boden-Albala B, Paik MC, Moon YP, Sacco RL et al (2009) Lipid profile components and risk of ischemic stroke: the Northern Manhattan Study (NOMAS). Arch Neurol 66:1400-1406

Yang G, Wang Y, Zeng Y, Gao GF, Liang X, Zhou M et al (2013) Rapid health transition in China, 1990-2010: findings from the Global Burden of Disease Study 2010. Lancet. 381:1987-2015

Yang QD, Niu Q, Zhou YH, Liu YH, Xu HW, Gu WP et al (2004) Incidence of cerebral hemorrhage in the Changsha community. A prospective study from 1986 to 2000. Cerebrovasc Dis 17:303-313

Zhang C, Qin YY, Chen Q, Jiang H, Chen XZ, Xu CL et al (2014) Alcohol intake and risk of stroke: a dose-response meta-analysis of prospective studies. Int J Cardiol 174:669-677

Zhang FL, Guo ZN, Wu YH, Liu HY, Luo Y, Sun MS et al (2017) Prevalence of stroke and associated risk factors: a population based cross sectional study from Northeast China. BMJ Open 7:e015758

Zhao JJ, He GQ, Gong SY, He L (2013) Status and costs of primary prevention for ischemic stroke in China. J Clin Neurosci 20:14271432

Zhou M, Wang H, Zhu J, Chen W, Liang X (2016) Cause-specific mortality for 240 causes in China during 1990-2013: a systematic subnational analysis for the Global Burden of Disease Study 2013. Lancet. 387:251-272

Publisher's note Springer Nature remains neutral with regard to jurisdictional claims in published maps and institutional affiliations. 